\title{
Social Determinants of Narcotics Use Susceptibility among School-Attending Adolescents in Bissau, Guinea-Bissau: A Cross-Sectional Analysis
}

\author{
Jon Edmund Bollom ${ }^{1, *(\mathbb{D})}$, Aladje Baldé ${ }^{2}$, Zeca Jandi ${ }^{3}$, Hamadou Boiro ${ }^{1,3}$, Jónína Einarsdóttir ${ }^{1} \mathbb{D}$ and \\ Geir Gunnlaugsson ${ }^{1}$ (D) \\ 1 Faculty of Sociology, Anthropology and Folkloristics, University of Iceland, Oddi, Saemundargata 6 , \\ IS-102 Reykjavík, Iceland; hboiro@gmail.com (H.B.); je@hi.is (J.E.); geirgunnlaugsson@hi.is (G.G.) \\ 2 University Campus, Jean Piaget University of Guinea-Bissau, Bissau 5100, Guinea-Bissau; aladje@gmail.com \\ 3 Instituto Nacional de Estudos e Pesquisa (INEP), Avenida dos Combatentes de Liberdade da Pátria, \\ Bissau 112, Guinea-Bissau; jandizeca@gmail.com \\ * Correspondence: jeb13@hi.is; Tel.: +354-831-8833
}

check for

updates

Citation: Bollom, J.E.; Baldé, A.; Jandi, Z.; Boiro, H.; Einarsdóttir, J.;

Gunnlaugsson, G. Social

Determinants of Narcotics Use

Susceptibility among

School-Attending Adolescents in

Bissau, Guinea-Bissau: A

Cross-Sectional Analysis. Adolescents

2021, 1, 306-320. https://doi.org/

10.3390 /adolescents1030023

Academic Editor: Dan Romer

Received: 13 May 2021

Accepted: 26 July 2021

Published: 3 August 2021

Publisher's Note: MDPI stays neutral with regard to jurisdictional claims in published maps and institutional affiliations.

Copyright: (c) 2021 by the authors. Licensee MDPI, Basel, Switzerland. This article is an open access article distributed under the terms and conditions of the Creative Commons Attribution (CC BY) license (https:// creativecommons.org/licenses/by/ $4.0 /)$

\begin{abstract}
Balanced medical and criminal justice approaches addressing determinants of alcohol and other drugs (AOD) use are central to achieving the United Nations Sustainable Development Goals 3 and 16. However, data on AOD use in resource-poor settings are characterised by relative paucity and anecdote. This study aimed to describe and analyse AOD use susceptibility and its determinants among school-attending adolescents in the capital Bissau, Guinea-Bissau. Survey data were collected through a locally adapted Planet Youth questionnaire in June 2017 across 16 schools in Bissau. The 2039-strong sample was selected through a multi-stage, random cluster process. Participants' lifetime alcohol use was $27.3 \%$, smoking $10.8 \%$, and cannabis use $3.6 \%$. In each instance, the ' 15 years and above' age bracket was the most common initiation period, signifying increased instigation in later adolescence. Subsequent Varimax Principal Component Analysis (PCA) of 312 variables captured data-driven models of AOD use susceptibility, implying imitated, polydrug use among initiates. Linear regression analysis revealed drinking, group violence, male gender, school dismissal and relationship breakdown as explanatory variables. Overlapping predictive variables suggest singular interventions may pre-empt myriad antisocial behaviours. PCA offers alternatives to singular, potentially myopic quantifications of drug use. PCA facilitates the creation of context-sensitive composite variables, enabling the identification of related outcome behaviours relevant to studies' sociocultural settings.
\end{abstract}

Keywords: survey and questionnaires; child; schools; Africa; western; health behaviour; alcohol drinking; smoking; cannabis; social determinants of health; principal component analysis

\section{Introduction}

The adoption of the Sustainable Development Goals 2016-2030 (SDGs) highlighted the international community's commitment to integrated cooperation across dimensions of economic, social, and environmental sustainability [1]. Over one-third of SDGs refer to young people implicitly or explicitly, an investment rationalised firstly by the demographic's sheer size. At 1.2 billion, those aged 15-24 years already represent $16 \%$ of the global population [2]. The projected growth of this demographic is estimated to be $62 \%$ in the world's 47 least developed states by 2050; for Sub-Saharan Africa, growth is estimated at $89 \%$ [2]. Furthermore, adolescence is a crucial period of development, wherein 'physical, cognitive, emotional, social, and economic resources' amassed inform health and life choices in later life [3].

Framed by SDG 3 (health and well-being) and SDG 16 (justice for all), the UN Office on Drugs and Crime likewise advocates interdisciplinary interventions on drug use [4]. 
Data suggest that those who begin smoking marijuana before 18 years are four to seven times more likely to develop a marijuana use disorder than adults [5]. Additionally, models of sequential drug use indicate that legal gateway drugs such as alcohol and tobacco precede more severe drug use and the initiation of criminal behaviours [6]. Identified as the peak of narcotics experimentation, interventions during adolescence offer opportunities to pre-empt the development of problematic behaviours [7]. Multidisciplinary intervention initiatives, supported by epidemiological studies, are required to avoid cycles of incarceration for which much of Sub-Saharan Africa's legal and physical infrastructure is ill-equipped to manage [8,9]. However, factoring in police interventions and lifetime productivity lost due to illness, interventions in adolescence are estimated to produce savings of $\$ 10$ for each $\$ 1$ spent [10].

Nonetheless, the epidemiology of alcohol and other drugs (AOD) use remains unclear [11,12], with further research necessary [13]. Drug use epidemiology is necessitated by the humanitarian and economic costs of current, unevenly felt discourses of incarceration. The annual cost of global incarceration surpasses $\$ 62.5$ billion, whilst the worldwide prison population has grown by $20 \%$ since 2000 [14]. The WHO estimates the cost of AOD use to be $2 \%$ of GDP for countries with available data [15]. Additionally, in 2015, drug abuse and addiction accounted for 17 million healthy life years lost worldwide, almost $1 \%$ of all ill-health in the world [14]; recent data indicate a higher risk of dying for youth aged 15-24 years than for children aged 1-5 years [16]. In 2015, around 5\% of the global population was estimated to have used narcotics, rising to 5.5\% in 2017, or otherwise approximately 271 million global users [4]; 11\% of users experienced drug dependence [14]. Despite data scarcity, a meta-analysis suggested 31\% of street children and youth in resource-constrained settings have a lifetime incidence of cannabis use, $7 \%$ of cocaine, and $47 \%$ of inhalants [17].

Policymakers in data-scarce settings must contend with a lack of socioeconomically sensitive data [18]. Despite presenting comparatively little data on drug use in South America and Africa [14], data returns from India and Nigeria suggest higher drug use in developing states than previously estimated [4]. Before Nigeria's data returns, little to no population-based data on drug usage existed in West Africa [19]. A dearth of longitudinal data restrict the estimation of longer-term trends.

\subsection{Determinants of Engagement}

Previous research shows some continuity in the definition of addiction through the utilisation of diagnostic frameworks, such as the DSM-IV or DSM-V frameworks. Contrarily, definitions of use and abuse remain relatively ambiguous, though patterned, physically, and mentally harmful engagement is signified. Within the context of international narcotics policy, 'drugs' may indicate any substance in Schedules I and II of the Single Convention on Narcotic Drugs, 1961 [20].

Research from higher-income settings suggests that determinants of AOD initiation may be divided into demographic and social categories. Studies on drug abuse often focus upon males, the vast majority of the incarcerated population [14], with literature suggesting that male gender alone predicts criminality [21-23]. Delinquency also peaks in late adolescence. However, age acts not as a mutually exclusive determinant of behaviour but rather as a modifier of social determinants, so that familial factors are thought to hold more significant sway in childhood, ceding to drug abusive peer relationships during adolescence [10].

Social determinants include socioeconomic status, economic inequality, integration with educational systems and the financial market, peer networks, familial relations, and mental health $[21,24,25]$. Socioeconomic status is not solely an apolitical dimension, and when measured by occupation, the link to criminal behaviours appears weak or non-existent [22]. However, when the calculation of socioeconomic status is sensitive to sustained socioeconomic disadvantage, and crime is defined more specifically as a severe delinquency, a more explicit link is evident. Increased cannabis use is identified in 
lower socioeconomic status individuals, where the apparent quality of staving off hunger incentivises cannabis use in Mozambique [26]. Accordingly, drug use is closely associated with detachment from the labour market and educational system [27]. School expulsion signifies a further breakdown in individuals' bonds to the educational system, representing an additional risk factor [28]. Where individuals suspect that peer integration is reliant upon substance use, they are identified as participating more in substance use [25]. Similarly, evidence indicates that alcohol consumption and positive self-esteem may be coincidental, suggesting that normalisation of alcohol use is synonymous with stabilising self-image with the group norm [29]. Peer modelling is thought to be of particular significance during periods of transition and increased vulnerability, such as moving home, school, or parental divorce [10]. Thus, it is suggested that self-esteem and peer influence feed into a nexus of mental health issues that predict delinquency. However, it remains unclear whether peer normalisation causes delinquency, or a confluence of risk factors elicits simultaneously the formation of problematic behaviours and deviant peer relations [28]. Parent-child relations, physical and sexual abuse, parental marital status and parental education are likewise predictive of substance use [30]. Similarly, the child's perception that their parents approve, or at least do not disapprove of their substance use, is predictive of increased drug use [25].

A key protective factor in low-income settings is the market worth of narcotics versus free capital in the local area. Thus, whilst the typical societal impact of local narcotics trafficking is overspill within low-income communities, organised trafficking networks are more able to efficiently direct narcotics towards more profitable target markets, limiting societal impact in such settings [31].

\subsection{Background to Study}

Located in West Africa, Guinea-Bissau's Human Development Index ranking of 175th out of 189 states [32] underlines prolonged faltering development and a post-colonial history characterised by political instability [33]. Guinea-Bissau scored 92.9 in the 2020 Fragile States Index, the 23rd highest of 178 states [34]. The entrenchment of a political, narcotic elite and insufficient educational provision have facilitated the infiltration of the narcotics trade into multiple tiers of the security administration [35]. Guinea-Bissau's population of 1.9 million is young, with $43 \%$ of the population under the age of 14 and $63 \%$ under 24 years [36]. Guinea-Bissau's population is ethnically, religiously, and linguistically diverse. Though a minority-spoken language, Portuguese is the official language of education. Dismal school enrolment rates between ages 6 and $11(66 \%$, as of 2014/15) and regular school year interruptions characterise education structures [37].

\subsection{Aims of the Study}

Despite its moniker as 'Africa's first narco state', there remains a dearth of drug use data in Guinea-Bissau. National drug policies appear informed by anecdotal estimates and proximate data based upon regional neighbours, indicating a consequent rise in cocaine use following trafficking network infiltration $[19,26]$. Here we aim to describe and analyse socio-economic and demographic determinants of AOD use susceptibility among school-attending adolescents in Bissau. The scope of the data utilised for this study, 'AOD use susceptibility' includes alcohol, tobacco, and cannabis. Focusing upon social determinants, this study utilises cross-sectional and linear regression analyses to develop a snapshot of statistically predictive social variables associated with undesirable behaviours. To capture data-driven models of AOD use, reducing the dataset into fewer dimensions, Varimax Principal Component Analysis (PCA) was utilised to answer the following research question: To what extent is AOD use susceptibility of school attending adolescents in the capital Bissau shaped by peers and socioeconomic determinants? 


\section{Materials and Methods}

\subsection{Survey Implementation}

This research draws on a survey implemented in Bissau in June 2017. The questionnaire, elaborated by Youth in Europe-a Drug Prevention Program, now Planet Youth [38], explores an array of social factors to map relevant risk and protective factors in narcotics and criminality engagement through 312 questions over 77 themes. The questionnaire was developed by a multidisciplinary team and has been used for over a decade by collaborating partners in Europe and elsewhere thereafter. The survey, the first of its kind in GuineaBissau, was translated into Portuguese, pilot-tested and adapted to the Bissau-Guinean cultural context.

Questionnaires were disseminated in schools across the country's most populous city, the capital Bissau, aiming to reach the highest possible number of participants within the 15 to 16-year-old target group. Through a random cluster process, a longlist of 116 classes, containing 4470 students from the 7 th to 10 th grades was reduced to a sample of 2110 students from 17 schools-12 public, 5 private-in Bissau, representing $47.2 \%$ of the initial longlist total; after randomisation, one private school withdrew from participation because of schedule clashes. When asked during the implementation, students responded with satisfaction at the opportunity to participate and there was ease of content comprehension. Of the 2110 student responses, 2039, or $96.6 \%$ of questionnaires, were successfully digitised by the Icelandic Centre for Social Research and Analysis (ICSRA) at Reykjavík University, representing the entirety of the survey sample for this research. Data were imported into the IBMSPSS Statistics 21.0 by ICSRA and numerically codified. Data were then imported into IBMSPSS 24.0 for data analysis; "don't know/doesn't apply" answers and missing values were excluded.

\subsection{Dependent Variable Modelling}

Quantifications of AOD use throughout the literature are myriad including, but not limited to, drug type, frequency of recent and lifetime use and interpretive measurements of use [39]. Scales of AOD use may equally draw upon the age of initiation, narcotic purity, or volume. The survey design utilised in data collection explores several dimensions of delinquency and drug use rather than singular measurements. Consequently, this study utilises multiple variables exploring individual and peer AOD use to identify an underlying, data-driven index variable of patterned drug behaviour, hinting at a cognitive decision-making framework regarding AOD use [40].

Varimax Principal Component Analysis (PCA) was performed on a longlist of available survey variables. An exploratory factor analysis allowed for the reduction of the dimensionality of the dataset by identifying underlying response patterns or components. Following the steep escalation of eigenvalues above the scree plot 'elbow', 16 components were considered significant (Figure 1). Cronbach's Alpha was consequently utilised to confirm the internal consistency of said components, with 11 components generating coefficients of reliability $(\alpha)$ above 0.7 . The analysis of said components allowed for the subsequent computation of new variables, hereafter identified as composite variables, using IBMSPSS 24.0. The computation of new composite variables based on these components was enabled without necessitating variable collapsing due to the consistent use of Likert scales throughout the questionnaire. The 11 composite variables were then given names based on their constituent variables. The constellation of variables informing the first composite variable, hereafter described as an index of AOD use susceptibility, is presented in Table 1. The composite variable 'AOD use susceptibility' was utilised as the dependent variable in linear regression analysis. The remaining composite variables were used in conjunction with selected survey variables as independents within the same model. 


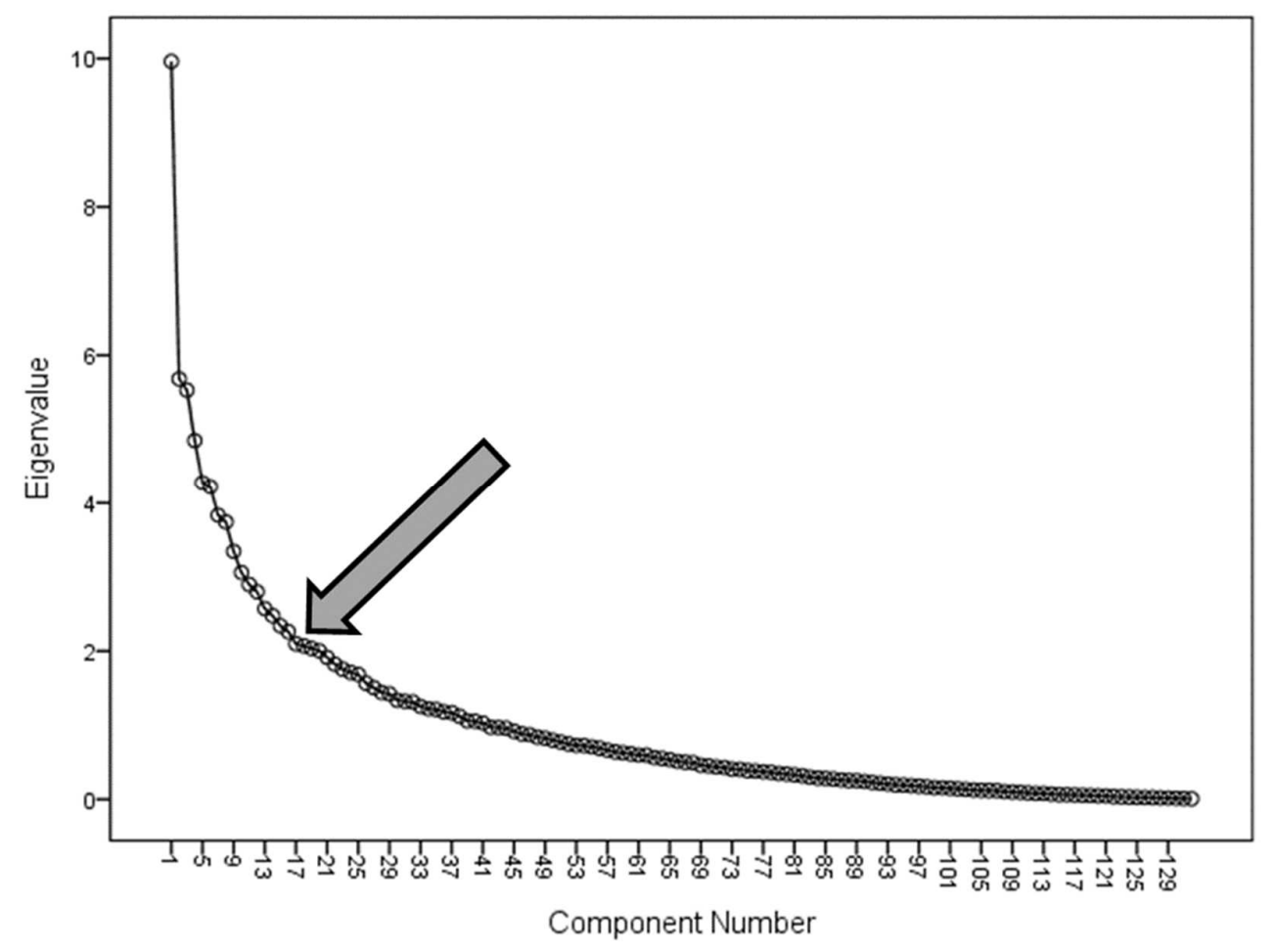

Figure 1. Scree plot indicating eigenvalues of components in PCA.

Table 1. Rotated Component Matrix indicating variable loadings for AOD use susceptibility, the component *

\begin{tabular}{|c|c|}
\hline \multirow{2}{*}{ Variable } & Component \\
\hline & 1 \\
\hline Q72a. How many of your friends do the following? Smoke cigarettes & 0.857 \\
\hline Q72b. How many of your friends do the following? Drink alcohol & 0.836 \\
\hline Q72c. How many of your friends do the following? Become drunk at least once a month & 0.801 \\
\hline Q72d. How many of your friends do the following? Smoke hash or marijuana & 0.731 \\
\hline Q72e. How many of your friends do the following? Fight with somebody & 0.532 \\
\hline Q72f. How many of your friends do the following? Pick fights or search out fights & 0.502 \\
\hline Q64b. At what age (if ever) did you do the following for the first time? Got drunk & 0.482 \\
\hline Q55. How often have you smoked cigarettes in your lifetime? & 0.450 \\
\hline Q66f. How often have you done the following in the last 12 months? Committed another offence & 0.402 \\
\hline Q61a. How often have you had an alcoholic drink of any kind? In your lifetime & 0.448 \\
\hline Q64e. At what age (if ever) did you do the following for the first time? Used cannabis (hash/marijuana) & 0.317 \\
\hline
\end{tabular}

* Extraction Method: PCA. Rotation Method: Varimax with Kaiser Normalization. Rotation converged in 50 iterations.

The composite variable 'AOD use susceptibility' examines both peer and individual tobacco and alcohol use, cannabis initiation age, and the incidence of brawls or fights. Consequently, this index was interpreted as AOD use susceptibility, where variables describing peer violence propensity were conceptualised as possible coinciding factors in AOD engagement, given their lower loadings relative to peer AOD use. The weight of variables exploring peer delinquency compared to individuals' reported engagement suggests peer behaviours signified the modelling of later often adopted behaviours. The term 'susceptibility' is employed to capture simultaneously the possible normalisation of problematic behaviours during adolescence through peer modelling, and an individual's vulnerability to negative emotional and behavioural development in light of such socioenvironmental influences. Thus, 'AOD use susceptibility' aims to describe statistically vulnerable adolescents socialising within peer groups already engaged in AOD use. Variables $72 \mathrm{e}$ and $72 \mathrm{f}$ also loaded upon the composite variable exploring violent crime, suggesting a thematic and behavioural overlap in these composite 
variables. However, as these variables loaded more heavily upon 'AOD use susceptibility', these were omitted from the composite variable 'violent crimine'.

Several composite variables showed anticipated thematic cohesion in their constitution, such that the composite variable exploring alcohol use addressed multiple variables exploring drinking habits. Unexpectedly, violent, and economic crime were also clearly delineated so that though the severity of economic crimes varied, from the theft of an item worth more than three movie tickets to the committing of more severe property offences, to the use of physical violence to steal, the motivation for misconduct remained financial. Contrarily, violent offences were not marked by the compulsion for economic advantage.

\subsection{Statistical Methods}

Independent variables for linear regression modelling were incorporated where the social determinants of AOD use susceptibility identified in the literature overlapped with survey variables. The theoretical foundations, and subsequent breadth of topics covered in the survey facilitated the incorporation of a number of survey variables exploring social determinants of AOD use previously discussed. Highlighted independent factors considered in the linear regression analyses are presented in Table 2 . Both the mother and father's education and occupation, originally 11 and 9-point answers, respectively, were collapsed into two 3-point indicators of parental education and work type. Engagement in higher education was defined as initiation, not necessarily completion, of trade school or university. Private school attendance was utilised as a proxy measurement of SES.

Listwise deletion of responses in linear regression modelling was exacerbated by the computation of composite variables from multiple variables. Consequently, multiple imputations were utilised to provide unbiased, confidence valid estimates of missing values across five imputed data sets. The pooled results, representing $n=2039$ responses, were used in regression analyses.

The model summary for AOD use susceptibility is presented in Table 3. Unfortunately, the calculation of $R^{2}$, adjusted $R^{2}$ values, or ANOVA components for pooled imputed datasets is currently unavailable through SPSS modules [41]. Subsequently, complete model summaries are presented, suggesting that between $52.6 \%$ and $59.2 \%$ of variance may be explained by the regression model across imputation numbers 1 , through 5 .

\subsection{Ethical Considerations}

Respondents deposited unmarked questionnaires into blank envelopes and sealed them. Questionnaires were assigned anonymous ID and Batch variables for individual school profile construction. Comprehension concerns were mitigated with support from one or two teachers, plus members of the research team, in each class (GG, ZJ, HB, JE).

The study was approved on 6 June 2017, by the then Minister of Education Dr. Sandji Fati (No/Ref 250/MEES/GM/2017), allowing the Jean Piaget Guinea-Bissau University and the University of Iceland to conduct research on the health and well-being of adolescents in Guinea-Bissau. The study was approved by the head-teachers at each participating school. Most of the participants were aged 14-17 years and children as defined by the Convention on the Rights of the Child (CRC) [42]. Vital components of the CRC are children's right to express an opinion on their situation (Art. 12) and to participate (Art. 3, 5, and 12) as found appropriate for their age. Considering the students' mature age and the setting in which the study was conducted, it was decided not to seek parental approval but allow the children themselves to decide on their participation, which was anonymous. 
Table 2. Frequency table of selected behavioural and experienced variables, by gender.

\begin{tabular}{|c|c|c|c|}
\hline Variable & Total (\%) & Boy (\%) & Girl (\%) \\
\hline \multicolumn{4}{|c|}{$\begin{array}{l}\text { Q25c. How many whole days have you been absent from school during the last } 30 \text { days for other reasons [than (a) because of illness } \\
\text { and (b) you "skipped" or "cut" classes]? }\end{array}$} \\
\hline None/Never & $606(49)$ & $325(50)$ & $281(49)$ \\
\hline 1 day & $326(27)$ & $169(26)$ & $157(27)$ \\
\hline 2 days & $182(15)$ & $94(14)$ & $88(15)$ \\
\hline 3-4 days & $53(4)$ & $33(5)$ & $20(3)$ \\
\hline 5-6 days & $20(2)$ & $10(2)$ & $10(2)$ \\
\hline 7 days or more & $40(3)$ & $20(3)$ & $20(3)$ \\
\hline Total & $1227(100)$ & $651(100)$ & $576(100)$ \\
\hline \multicolumn{4}{|c|}{ Q47k. Have you ever experienced a breakup with a boyfriend/girlfriend? } \\
\hline Yes, during the last 30 days & $246(15)$ & $119(15)$ & $127(16)$ \\
\hline Yes, during the last 12 months & $212(13)$ & $109(14)$ & $103(13)$ \\
\hline Yes, more than 12 months ago & $203(13)$ & $112(14)$ & $91(11)$ \\
\hline Never & 937 (59) & $451(57)$ & $486(60)$ \\
\hline Total & $1598(100)$ & $791(100)$ & $807(100)$ \\
\hline \multicolumn{4}{|c|}{ Q47p. Have you ever been dismissed from class or sent to the disciplinary board? } \\
\hline Yes, during the last 30 days & $121(8)$ & $63(8)$ & $58(7)$ \\
\hline Yes, during the last 12 months & $73(5)$ & $40(5)$ & $33(4)$ \\
\hline Yes, more than 12 months ago & $93(6)$ & $59(7)$ & $34(4)$ \\
\hline Never & $1304(82)$ & $633(80)$ & $671(84)$ \\
\hline Total & $1591(100)$ & $795(100)$ & $796(100)$ \\
\hline \multicolumn{4}{|c|}{ Q67a. Have you been a victim of physical violence during the last 12 months? } \\
\hline Never & $1498(84)$ & $719(82)$ & $779(85)$ \\
\hline Once & $211(12)$ & 109 (13) & $102(11)$ \\
\hline 2 to 5 times & $47(3)$ & $29(3)$ & $18(2)$ \\
\hline 6 to 9 times & $12(0.7)$ & $8(1)$ & $4(0.4)$ \\
\hline 10 to 13 times & $6(0.3)$ & $2(0.2)$ & $4(0.4)$ \\
\hline 14 to 17 times & $4(0.2)$ & $3(0.3)$ & $1(0.1)$ \\
\hline 18 times or more & $9(0.5)$ & $4(0.5)$ & $5(0.5)$ \\
\hline Total & $1787(100)$ & $874(100)$ & $913(100)$ \\
\hline \multicolumn{4}{|c|}{ Q69f. How often, during the last 12 months, have you been in a group that was attacked by another group? } \\
\hline Never & $1425(86)$ & $700(87)$ & 725 (87) \\
\hline Once & $141(9)$ & $70(9)$ & $71(9)$ \\
\hline Twice & $36(2)$ & $21(3)$ & $15(2)$ \\
\hline 3 to 4 times & $13(1)$ & $9(1)$ & $4(1)$ \\
\hline 5 times or more & $33(2)$ & $17(2)$ & $16(2)$ \\
\hline Total & $1648(100)$ & $817(100)$ & $831(100)$ \\
\hline
\end{tabular}

Table 3. Model summary for AOD use susceptibility across original and imputed data sets.

\begin{tabular}{|c|c|c|c|c|c|c|c|c|c|c|}
\hline \multirow{2}{*}{$\begin{array}{l}\text { Imputation } \\
\text { Number }\end{array}$} & \multirow[b]{2}{*}{ Model } & \multirow[b]{2}{*}{$\mathbf{R}$} & \multirow{2}{*}{ R Square } & \multirow{2}{*}{$\begin{array}{l}\text { Adjusted } \\
\text { R Square }\end{array}$} & \multirow{2}{*}{$\begin{array}{l}\text { Std. Error of the } \\
\text { Estimate }\end{array}$} & \multicolumn{5}{|c|}{ Change Statistics } \\
\hline & & & & & & $\begin{array}{l}\text { R Square } \\
\text { Change }\end{array}$ & F Change & df1 & df2 & $\begin{array}{l}\text { Sig. F } \\
\text { Change }\end{array}$ \\
\hline Original data & 1 & $0.767^{\mathrm{a}}$ & 0.589 & 0.526 & 0.41371 & 0.589 & 9.472 & 45 & 298 & 0.000 \\
\hline 1 & 1 & $0.775^{b}$ & 0.601 & 0.592 & 0.46255 & 0.601 & 66.779 & 45 & 1993 & 0.000 \\
\hline 2 & 1 & $0.769^{c}$ & 0.592 & 0.582 & 0.46185 & 0.592 & 64.135 & 45 & 1993 & 0.000 \\
\hline 3 & 1 & $0.764^{\mathrm{d}}$ & 0.584 & 0.575 & 0.45911 & 0.584 & 62.276 & 45 & 1993 & 0.000 \\
\hline 4 & 1 & $0.766^{\mathrm{e}}$ & 0.587 & 0.578 & 0.45816 & 0.587 & 62.996 & 45 & 1993 & 0.000 \\
\hline 5 & 1 & $0.761^{\mathrm{f}}$ & 0.578 & 0.569 & 0.46502 & 0.578 & 60.781 & 45 & 1993 & 0.000 \\
\hline
\end{tabular}




\section{Results}

\subsection{Descriptive Statistics}

Table 4 details the demographic composition of respondents. The sample closely mirrors Bissau-Guinean society at the 15-24 year age bracket for gender ratio (0.96 male/female ratio [36]).

Table 4. Frequency table of selected socioeconomic and demographic variables, by gender.

\begin{tabular}{|c|c|c|c|}
\hline Variable & Total $(\%)$ & Boy (\%) & Girl (\%) \\
\hline \multicolumn{4}{|c|}{ Q1. Are you a boy or a girl? } \\
\hline & $1978(100)$ & $954(48)$ & $1024(52)$ \\
\hline \multicolumn{4}{|c|}{ Q2. How old are you? (years) } \\
\hline 14 & $130(7)$ & $55(6)$ & $75(8)$ \\
\hline 15 & 346 (19) & $166(19)$ & $180(19)$ \\
\hline 16 & $435(24)$ & $194(22)$ & $241(26)$ \\
\hline 17 & $581(32)$ & $305(35)$ & $276(29)$ \\
\hline 18 & $288(16)$ & $139(16)$ & $149(16)$ \\
\hline $19+$ & $45(2)$ & $22(3)$ & $23(2)$ \\
\hline Total & $1825(100)$ & $881(100)$ & $944(100)$ \\
\hline \multicolumn{4}{|c|}{ Q3. Grade/Class in school } \\
\hline 7 th grade & $40(2)$ & $19(2)$ & $21(2)$ \\
\hline 8 th grade & $757(39)$ & $354(38)$ & $403(40)$ \\
\hline 9th grade & $908(47)$ & $442(48)$ & $466(47)$ \\
\hline 10th grade & $224(12)$ & $112(12)$ & $112(11)$ \\
\hline Total & $1929(100)$ & $927(100)$ & $1002(100)$ \\
\hline \multicolumn{4}{|c|}{ Type of school } \\
\hline Public & $1033(52)$ & $530(56)$ & $503(49)$ \\
\hline Private & $945(48)$ & $424(44)$ & $521(51)$ \\
\hline Total & $1978(100)$ & $954(100)$ & $1024(100)$ \\
\hline \multicolumn{4}{|c|}{ Q5Q7. Both parents educated } \\
\hline $\begin{array}{l}\text { Neither parent } \\
\text { educated }\end{array}$ & $604(36)$ & $298(37)$ & $306(34)$ \\
\hline One parent educated & $538(32)$ & $277(34)$ & $261(29)$ \\
\hline $\begin{array}{l}\text { Both parents } \\
\text { educated }\end{array}$ & $553(32)$ & $231(29)$ & $322(36)$ \\
\hline Total & $1695(100)$ & $806(100)$ & $889(100)$ \\
\hline \multicolumn{4}{|c|}{ Q9Q10. Both parents work outside of the home } \\
\hline $\begin{array}{l}\text { Neither parent } \\
\text { outside the home }\end{array}$ & $283(15)$ & $146(16)$ & $137(14)$ \\
\hline $\begin{array}{l}\text { One parent works } \\
\text { outside the home }\end{array}$ & $844(45)$ & $408(45)$ & $436(45)$ \\
\hline $\begin{array}{l}\text { Both parents work } \\
\text { outside the home }\end{array}$ & $751(40)$ & $351(39)$ & $400(41)$ \\
\hline Total & $1878(100)$ & $905(100)$ & $973(100)$ \\
\hline
\end{tabular}

The disparity between respondents' mean age (16.38) and grades (8.79) and varying value ranges suggest an unbalanced academic profile, as children should first enrol aged six. Late enrolment and repeating of the academic year appear commonplace within the sample, mirroring national trends. Combined collapsed variables examining parental education and work reveal at least one of $64.7 \%$ of respondents' parents have begun trade school or university. Figure 2 indicates age of initiation of AOD use. Drinking initiation rises with age, with the 15 and above age category capturing the largest single group of initiators. Lifetime smoking incidence was $10.8 \%$, though initiation at 11 years or younger was almost as large a group as the 
oldest category. Cannabis engagement was relatively low, with only $3.6 \%$ of students indicating lifetime use, almost half of which (1.6\%) began smoking aged 15 or above.

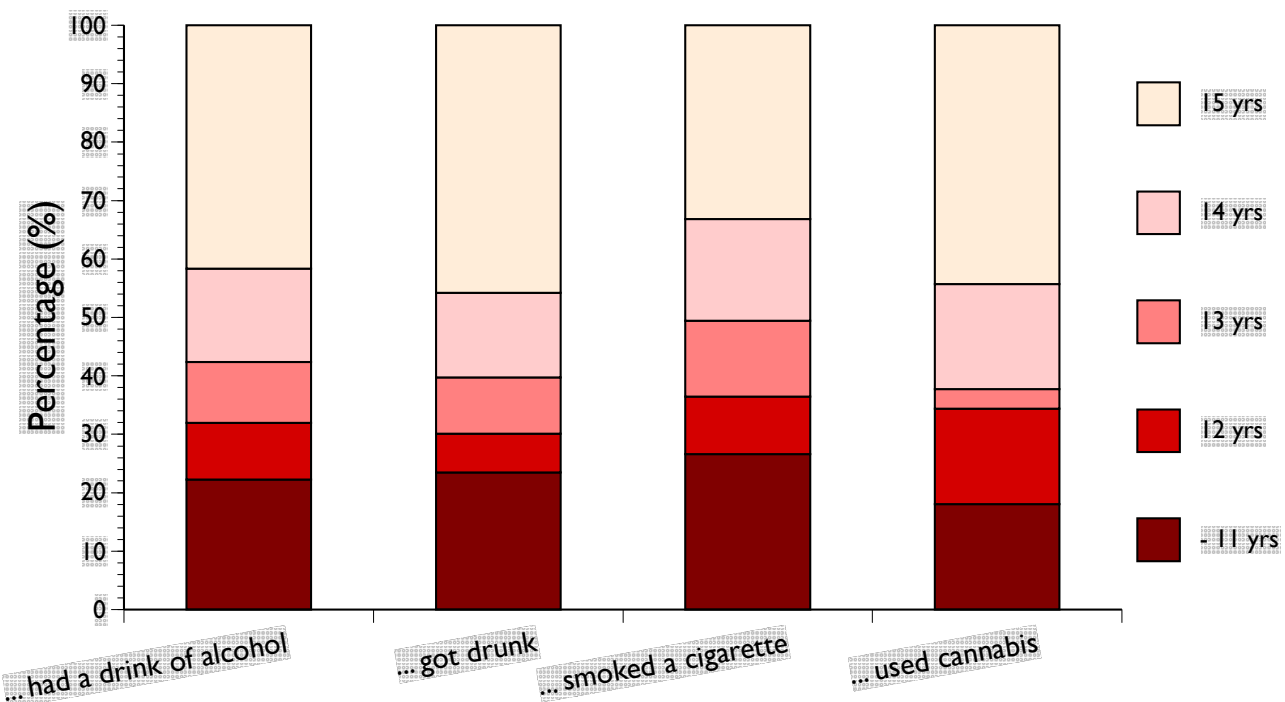

Figure 2. Age of initiation (years) amongst respondents who have begun AOD use.

\subsection{Cross-Sectional Statistics}

Owing to the range of variables explored, for conciseness, only the regression analyses of predictive variables discussed hereafter are presented in Table 5. A full list of variables and their coefficients are available in Supplementary Materials, Table S1. Results indicate that age was not predictive of AOD use susceptibility, though male gender was. Likewise, private schooling, theorised an upstream determinant of SES, did not predict AOD use susceptibility. However, frequent dismissal indicated a rising AOD engagement.

Table 5. Selected coefficient values for the computed composite variable 'AOD use susceptibility' *.

\begin{tabular}{|c|c|c|c|c|c|c|}
\hline & \multicolumn{2}{|c|}{$\begin{array}{l}\text { Unstandardised } \\
\text { Coefficients }\end{array}$} & \multirow{2}{*}{$t$} & \multirow{2}{*}{ Sig. } & \multicolumn{2}{|c|}{$\begin{array}{l}\text { 95\% Confidence } \\
\text { Interval for B }\end{array}$} \\
\hline & B & Std. Error & & & Lower Bound & Upper Bound \\
\hline (Constant) & 0.425 & 0.236 & 1.800 & 0.074 & -0.041 & 0.890 \\
\hline Economic crime & 0.171 & 0.033 & 5.174 & 0.000 & 0.102 & 0.240 \\
\hline Violent crime & 0.059 & 0.016 & 3.671 & 0.000 & 0.027 & 0.091 \\
\hline Cannabis risk perception & 0.000 & 0.008 & -0.019 & 0.985 & -0.016 & 0.015 \\
\hline Parental oversight & 0.042 & 0.015 & 2.731 & 0.008 & 0.011 & 0.072 \\
\hline Drinking & 0.395 & 0.015 & 25.559 & 0.000 & 0.364 & 0.426 \\
\hline Age & -0.003 & 0.010 & -0.281 & 0.779 & -0.023 & 0.017 \\
\hline Gender & -0.061 & 0.023 & -2.695 & 0.007 & -0.106 & -0.017 \\
\hline A breakup with a boyfriend/girlfriend & -0.035 & 0.010 & -3.491 & 0.001 & -0.055 & -0.015 \\
\hline $\begin{array}{l}\text { Been dismissed from class, or sent to the } \\
\text { disciplinary board }\end{array}$ & -0.048 & 0.018 & -2.705 & 0.016 & -0.086 & -0.010 \\
\hline $\begin{array}{l}\text { Been a victim of physical violence during } \\
\text { the last } 12 \text { months }\end{array}$ & 0.072 & 0.019 & 3.760 & 0.001 & 0.033 & 0.112 \\
\hline $\begin{array}{l}\text { Been in a group that was attacked by } \\
\text { another group during the last } 12 \text { months }\end{array}$ & 0.094 & 0.019 & 4.836 & 0.000 & 0.055 & 0.133 \\
\hline
\end{tabular}

* Full list of coefficient values is found in Supplementary Materials, Table S1.

Both violent and acquisitive criminal behaviours predicted AOD use susceptibility. Membership in groups that were teased, or were attacked by others, predicted AOD use susceptibility, as was being assaulted within the previous 12 months regardless of 
group affiliation. Increased drinking behaviours were the strongest predictors of AOD use susceptibility of any independent variable.

\section{Discussion}

Guinea-Bissau occupies a curious niche in drug use literature; one of growing importance to discussions of narcotics network infiltration and security and concurrent obscurity in terms of data upon absolute drug use engagement. This study, conducted among schoolattending adolescents in Bissau, the capital of the Republic of Guinea-Bissau, indicates that PCA simultaneously offers alternatives to a singular and potentially myopic quantifications of AOD use in data analyses and facilitates the creation of context-sensitive outcome variables. The simultaneous identification of overlapping predictive behaviours, as relevant to the socio-cultural context of the study, is therefore enabled.

Models of progressive drug use, wherein gateway narcotics are theorised to precede the initiation of progressively 'harder' narcotics, suggest interventions targeting singular drug types may interrupt progression to consequent drug types [6,35]. The identification of patterned drug use within the composite variable 'AOD use susceptibility' using PCA, and declining use of drugs from alcohol, tobacco to cannabis, suggests that progressive drug use models suit this sample. Consequently, interventions addressing gateway drugs may simultaneously inhibit subsequent drug use initiation. Despite a lack of population-based data on national drug use, concerns over increased cocaine use because of Guinea-Bissau's centrality to transatlantic cocaine trafficking networks may therefore be pre-empted by the programming of interventions tackling gateway drugs such as alcohol and tobacco before sequential drug engagement begins, as per the findings of this research. Furthermore, the identification of non-stigmatising, overlapping determinants of drug use susceptibility through regression analyses, such as relationship breakdown, dismissal from class and engagement in studies, present avenues for non-disparaging, targeted interventions pre-empting delinquency. The linear relationship between several composite variables, including violence, acquisitive criminality, alcohol use, and AOD use susceptibility, suggests that singular intervention methodologies may address multiple problematic outcome behaviours by targeting shared predictive determinants [24].

Of particular importance to the programming of interventions in low-income contexts is the applicability and appropriateness of findings from research conducted in higherincome settings [31]. The results of this research indicate both overlap and deviation from the findings of research conducted in such settings, suggesting the statistical significance of the socio-cultural context of the sample. Thus, factors such as gender, romantic relationship breakdown, peer modelling of delinquency, class expulsion, parental oversight, alcohol use and criminality predicted drug use, as in the literature. Yet, contrasting with previous studies, this research found no predictive value for variables including age, socioeconomic status, parental occupation or education, absenteeism, or cannabis risk perception and the outcome variable, 'AOD use susceptibility'. A discussion of those variables that did not predict AOD use susceptibility, despite previous research, is necessitated.

Age has previously been demonstrated to predict increasing delinquency, with problematic behaviours peaking in late adolescence [7], as risk factors accumulate between 10 and 17 years of age $[21,25]$. Yet, this study does not reflect these findings. However, as antisocial behaviours peak in late adolescence before plateauing, a linear regression model may not provide an adequate descriptive model. Students are also likely to establish peer relationships with their classmates. Yet, the possible socialisation of behaviours and attitudes across age groups may confound findings within this sample, where mixed age demographics typifies classes and groups of peers of similar age referred to as 'mandjuandade' [43].

Socioeconomic status remains a contentiously debated independent predictor of drug use and a complex variable, itself an expression of multiple upstream determinants [22,28]. Within this research, private school attendance, previously utilised as a proximate valuation of family socioeconomic status [44], showed no significant relation to AOD use 
susceptibility, standing in contrast to previous findings [28,40]. However, higher parental education levels suggest the sample represents a disproportionately privileged segment of society, able to access the greater relative emotional and institutional resources that influence later health outcomes [45]. Parental occupation and education are identified as risk factors in AOD use [22,30]. Within this sample, high parental education levels suggest a disproportionately high rate of parental educational attainment within the sample group against a national literacy rate of $46 \%$ [46]. This study suggested no relationship between the aforementioned variables.

Dissociation with employment and educational structures has been highlighted as a risk factor in problematic behaviours [27,47]. Thus, expulsion from class and regular absences are identified as risk factors in the onset of problematic behaviours [28]. Within the sample, frequent dismissal, yet not absence, predicted increased values for the composite variable 'AOD engagement susceptibility'. However, the potential significance of absenteeism upon criminal behaviours may be impacted by the Bissau-Guinean context, where interruptions to schooling are commonplace. For example, budgetary incompletion resulted in multiple disruptions to the academic school year in 2017 [48]. Likewise, $25.7 \%$ of girls and $17.5 \%$ of boys aged $10-11$ years had already dropped out of school [49], suggesting absence may be less indicative of deviant behaviours and more indicative of youth employment and alternative familial roles and duties beyond students' educational responsibilities.

Perceptions of cannabis use were not predictive of AOD use susceptibility. Despite the previous linkage of awareness with reduced AOD use [10,50], Strang et al. argue awareness campaigns alone confer no positive effect and may increase initiation of cannabis use [51]. A mean of $4.0586(\mathrm{SD}=1.59998)$ in the 'cannabis risk perception' composite variable suggests respondents remain largely unaware of narcotics risks. Thus, we cannot assume that their (lack of) awareness is causally linked with narcotics use. The ambiguity shown regarding the dangers of AOD use implies parental attitudes are not widely impressed upon the sample. Where parental attitudes are impressed, they are not informed by drug risk awareness.

\subsection{Determinants of AOD Use}

This research did find some overlap with existing literature. As with previous studies, male gender was identified as predictive of delinquency [21,22]. These have suggested that culturally defined, gendered responses to stressors lead males to react violently, whilst females react through reversion to an emotional state [25]. Where the composite variable 'AOD use susceptibility' also interrogates peer brawling, our findings suggest that female coping strategies appear more effective regarding antisocial behaviour avoidance in trauma resolution.

Reflecting the findings of previous studies, this research suggests that the inability to maintain romantic relationships is predictive of escalated AOD use susceptibility during adolescence [52]. Thus, more recent breakups indicated increased AOD use susceptibility, initially suggesting that consequent emotional upheaval precludes AOD engagement. Despite more comprehensive peer bonds being identified as predictors of problematic behaviours [25], this research did not identify a linear relationship between the possibility of receiving 'caring and warmth' from peers and AOD use susceptibility. However, the composition of the variable 'AOD use susceptibility' suggests closely patterned observation and initiation of socialised behaviours. Deviant peer relationships and their statistical links to individuals' problematic behaviours are widely recognised in the literature $[14,50]$. Additionally, the simultaneous influence of physical abuse upon values of 'AOD use susceptibility' suggests that variables exploring the quality of care respondents received determined an individual's drug use. Finally, the impact of the composite variable, 'parental oversight' upon AOD use susceptibility, complements previous findings, where combined parental and adolescent coaching showed the most significant influence on adolescent drinking levels $[53,54]$. 
Linear regression revealed alcohol behaviours to predict AOD use susceptibility, and PCA indicated thematic overlap regarding alcohol use. Alcohol behaviours were the single most significant predictor of AOD use susceptibility within this group, suggesting polydrug use among those that have already initiated AOD use within the sample. Yu identifies alcohol as a 'gateway drug' [6], supporting findings of overlap within this study. Mirroring previous research $[6,55,56]$, the outcome variable 'AOD use susceptibility' was predicted by violent and acquisitive criminality and group violence. In each instance, increased exposure to physical violence and crime predicted increased engagement in problematic behaviours and AOD use susceptibility, supporting findings suggesting that problematic behaviours are observed and emulated [57].

\subsection{Strengths and Limitations}

The study is the first of its kind in the setting [44], providing the first socially sensitive insights into the social determinants of drug use amongst school attending youths in Bissau. Furthermore, through PCA, identifying the statistical association of alcohol, tobacco, and marijuana within the singular index variable, 'AOD use susceptibility', hints at patterned, polydrug use. The methodology applied suggests that interventions addressing multiple drug types may prove equally effective to those approaches focussing upon individual narcotics types. However, the resource-poor context of this research and repeated interruptions to educational provision hinder coordinated interventions. Thus family-centred social influence-based interventions, which have previously shown to produce a reduction in weekly alcohol drunkenness and use of $12.4 \%$ and $10.5 \%$, respectively [53], and utilise independent adolescent learning modules in addition to parental rule-making instruction [54], are advocated.

Both socioeconomic and cultural contexts have been demonstrated to play a role in behavioural outcomes, suggesting that culturally sensitive modifications should be considered before the advocacy of specific programming. Thus, the utilisation of questionnaires in schools indicates the unavoidable occlusion of non-school-attending adolescents. Street children across the continent have a higher likelihood of engagement with psychoactive substances [26]. Hence AOD use rates may be higher among an un-surveyed group than the sample. As those aged 24 years or younger represent the national majority [36], and school enrolment remains low, a significant proportion of the nation's population is not represented by this sample and needs to be addressed in further studies.

\section{Conclusions}

This study sought to reduce multiple variables exploring several dimensions of drug use into a single numerical value to simultaneously simplify data analyses and provide a nuanced behavioural profile of associated drug use behaviours through the utilisation of PCA. Furthermore, multiple linear regression allowed for the identification of coinciding behaviours, facilitating the programming of preventative interventions targeting secondary, often non-criminal risk factors influencing AOD use. Linear regression analysis revealed drinking and group violence, male gender, school dismissal and relationship breakdown as explanatory variables. The programming of interventions aimed at young people, based on our findings, is advocated. Yet, a deeper understanding of unobserved links between risk factors and AOD use and the preventative impact of advocated approaches is best informed by successive questionnaire rollouts, providing longitudinal perspectives on intervention effectiveness. The results presented suggest overlap in common risk factors between the Bissau-Guinean context and settings elsewhere. Nonetheless, the lack of a linear relationship between age, drug-risk awareness, and AOD use susceptibility hints at socio-culturally specific risk and protective factors, whose identification and mitigation are undermined by national and regional data scarcity.

Supplementary Materials: The following are available online at https:/ / www.mdpi.com/article/10 .3390 /adolescents1030023/s1, Table S1: Table of coefficients of multiple regression analyses. 
Author Contributions: Conceptualisation, J.E.B., A.B., Z.J., H.B., J.E. and G.G.; methodology, J.E.B., A.B., Z.J., H.B., J.E. and G.G.; validation, J.E.B. and G.G.; formal analysis, J.E.B. and G.G.; investigation, J.E.B., A.B., Z.J., H.B., J.E. and G.G.; resources, J.E. and G.G.; data curation, J.E.B. and G.G.; writingoriginal draft preparation, J.E.B. and G.G.; writing-review and editing, J.E.B., A.B., Z.J., H.B., J.E. and G.G.; supervision, G.G.; project administration, A.B., Z.J., H.B., J.E. and G.G.; funding acquisition, J.E. and G.G. All authors have read and agreed to the published version of the manuscript.

Funding: The Research Fund of the University of Iceland and funds from the School of Social Sciences, University of Iceland, Icelandic Centre for Social Research and Analysis (ICSRA), Reykjavík University, and Erasmus+ staff mobility grants.

Institutional Review Board Statement: Not applicable.

Informed Consent Statement: Prior parental approval for survey implementation was not sought. Before the distribution of questionnaires in each class, the authors (Z.J., H.B., J.E., G.G.) explained the study. Delivery of anonymous, filled-in questionnaires in a sealed envelope was taken as a consent to participation.

Data Availability Statement: The data underlying this article will be shared on request to the corresponding author. The data are not publicly available as they are part of a larger study with further analysis in progress.

Acknowledgments: The research represents a collaborative effort. We would like to extend our gratitude to the students, teachers and head-teachers in participating schools; Minister of Education at the time, Sandji Fati, for authorising the study; João Ribeiro Butiam Có, who contributed to the translation and preparation of the survey questionnaire and facilitated the creation of the research group in Bissau; Inga Dóra Sigfúsdóttir, Álfgeir Logi Kristjánsson, Hrefna Pálsdóttir, Margrét Lilja Guðmundsdóttir, and Jón Sigfússon of ICSRA for the support for electronic data transformation of questionnaires for data analysis, and encouragement to implement the survey under the umbrella of Planet Youth; and Stefán Pór Gunnarsson, the Social Science Institute, University of Iceland, for statistical advice.

Conflicts of Interest: The authors declare no conflict of interest. The funders had no role in the design of the study other than permitting the use of an adapted version of the Planet Youth questionnaire for the survey. They did not influence the collection, analyses, or interpretation of data, affect the conclusions drawn, or opinions stated, nor the decision to publish the results.

\section{References}

1. United Nations Development Programme. The Sustainable Development Goals Report 2017; United Nations: New York, NY, USA, 2017. Available online: https://unstats.un.org/sdgs/files/report/2017/thesustainabledevelopmentgoalsreport2017.pdf (accessed on 14 April 2021).

2. United Nations Department of Economic and Social Affairs. International Youth Day, 12 August 2019; United Nations: New York, NY, USA, 2019. Available online: https://www.un.org/development/desa/youth/wp-content/uploads/sites/21/2019/08 /WYP2019_10-Key-Messages_GZ_8AUG19.pdf (accessed on 14 April 2021).

3. Patton, G.C.; Sawyer, S.M.; Santelli, J.S.; Ross, D.A.; Afifi, R.; Allen, N.B.; Arora, M.; Azzopardi, P.; Baldwin, W.; Bonell, C.; et al. Our Future: A Lancet Commission on Adolescent Health and Wellbeing. Lancet 2016, 387, 2423-2478. [CrossRef]

4. United Nations Office on Drugs and Crime. World Drug Report 2019. Executive Summary; United Nations: New York, NY, USA, 2019. Available online: https://wdr.unodc.org/wdr2019/prelaunch/WDR19_Booklet_1_EXECUTIVE_SUMMARY.pdf (accessed on 14 April 2021).

5. National Institute on Drug Use. Media Guide: How to Find What You Need to Know about Drug Use and Addiction. 2018. Available online: https:/ / www.drugabuse.gov / sites/default/files/media_guide.pdf (accessed on 15 June 2021).

6. Yu, J. Alcohol, Cocaine, and Criminality: Specifying an Interaction Effect Model. J. Crim. Justice 1998, 26, 237-249. [CrossRef]

7. Pierce, M.; Hayhurst, K.; Bird, S.M.; Hickman, M.; Seddon, T.; Dunn, G.; Millar, T. Insights into the Link between Drug Use and Criminality: Lifetime Offending of Criminally-Active Opiate Users. Drug Alcohol Depend. 2017, 179, 309-316. [CrossRef]

8. Madeira, L.F.; Laurent, S.; Roque, S. The International Cocaine Trade in Guinea-Bissau: Current Trends and Risks. Noref Working Paper. 2011, pp. 1-18. Available online: https:/ / www.files.ethz.ch/isn/137866/international\%20cocaine\%20trade.pdf (accessed on 14 April 2021).

9. Csete, J.; Kamarulzaman, A.; Kazatchkine, M.; Altice, F.; Balicki, M.; Buxton, J.; Cepeda, J.; Comfort, M.; Goosby, E.; Goulão, J.; et al. Public Health and International Drug Policy. Lancet 2016, 387, 1427-1480. [CrossRef] 
10. United States Department of Health \& Human Services. Preventing Drug Use among Children and Adolescents. A Research Based Guide for Parents, Educators and Community Leaders, 2nd ed.; United States Department of Health \& Human Services: Washington, DC, USA, 2020. Available online: https:/ / www.drugabuse.gov/sites/default/files/preventingdruguse_2.pdf (accessed on 15 April 2021).

11. Medina-Mora, M.E. Prevention of Substance Abuse: A Brief Overview. World Psychiatry 2005, 4, 25-30. Available online: https://www.ncbi.nlm.nih.gov/pmc/articles/PMC1414714/ (accessed on 15 April 2021).

12. Stockings, E.; Hall, W.D.; Lynskey, M.; Morley, K.I.; Reavley, N.; Strang, J.; Patton, G.; Degenhardt, L. Prevention, Early Intervention, Harm Reduction, and Treatment of Substance Use in Young People. Lancet Psychiatry 2016, 3, 280-296. [CrossRef]

13. Dahlberg, L.L.; Toal, S.B.; Swahn, M.; Behrens, C.B. Measuring Violence-Related Attitudes, Behaviors, and Influences among Youths: A Compendium of Assessment Tools, 2nd ed.; Centers for Disease Control and Prevention: Atlanta, GA, USA, 2005. Available online: https:/ / www.cdc.gov/violenceprevention/pdf/YV_Compendium.pdf (accessed on 14 April 2021).

14. United Nations Office on Drugs and Crime. Treatment and Care for People with Drug Use Disorders in Contact with the Criminal Justice System. Alternatives to Conviction or Punishment; United Nations: New York, NY, USA, 2019. Available online: https://www.unodc. org/documents/justice-and-prison-reform/UNODC_WHO_Alternatives_to_Conviction_or_Punishment_2018.pdf (accessed on 15 April 2021).

15. International Narcotics Control Board. Primary Prevention of Drug Use. 2009. Available online: https://www.incb.org/ documents/Publications / AnnualReports/Thematic_chapters/English/AR_2009_E_Chapter_I.pdf (accessed on 15 June 2021).

16. Masquelier, B.; Hug, L.; Sharrow, D.; You, D.; Mathers, C.; Gerland, P.; Alkema, L. Global, Regional, and National Mortality Trends in Youth Aged 15-24 Years between 1990 and 2019: A Systematic Analysis. Lancet Glob. Health 2021, 9, e409-e417. [CrossRef]

17. Embleton, L.; Mwangi, A.; Vreeman, R.; Ayuku, D.; Braitstein, P. The Epidemiology of Substance Use among Street Children in Resource-Constrained Settings: A Systematic Review and Meta-Analysis: Street Children and Substance Use: A Review. Addiction 2013, 108, 1722-1733. [CrossRef]

18. United Nations Office on Drugs and Crime. International Standards on Drug Use Prevention, 2nd ed.; United Nations: New York, NY, USA, 2018. Available online: https://www.unodc.org/documents/prevention/UNODC-WHO_2018_prevention_standards_ E.pdf (accessed on 12 April 2021).

19. Csete, J.; Sanchez, C. Telling the Story of Drugs in West Africa: The Newest Front in a Losing War? Global Drug Policy Observatory Swansea: Swansea, UK, 2013; pp. 1-18. Available online: https://www.swansea.ac.uk/media/West-Africa-A-New-Front-in-aLosing-War.pdf (accessed on 15 April 2021).

20. United Nations Office on Drugs and Crime. Terminology and Information on Drugs; United Nations Office on Drugs and Crime (UNODC): New York, NY, USA, 2016. Available online: https://www.unodc.org/documents/scientific/Terminology_and_ Information_on_Drugs-E_3rd_edition.pdf (accessed on 15 April 2021).

21. Aslam, N. Drug Addiction, Criminality and Birth Order. J. Alcohol Drug Depend. 2014, 3, 1-12. [CrossRef]

22. Aaltonen, M.; Kivivuori, J.; Martikainen, P. Social Determinants of Crime in a Welfare State: Do They Still Matter? Acta Sociol. 2011, 54, 161-181. [CrossRef]

23. Gjeruldsen, S.R.; Myrvang, B.; Opjordsmoen, S. Criminality in Drug Addicts: A Follow-Up Study over 25 Years. Eur. Addict. Res. 2004, 10, 49-55. [CrossRef]

24. United States Department of Health \& Human Services. Facing Addiction in America. The Surgeon General's Report on Alcohol, Drugs and Health; United Nations: New York, NY, USA, 2016.

25. Whitesell, M.; Bachand, A.; Peel, J.; Brown, M. Familial, Social, and Individual Factors Contributing to Risk for Adolescent Substance Use. J. Addict. 2013, 2013, 1-9. [CrossRef]

26. Odejide, A.O. Status of Drug Use/Abuse in Africa: A Review. Int. J. Ment. Health Addict. 2006, 4, 87-102. [CrossRef]

27. Ólafsdóttir, H.; Bragadóttir, R. Crime and Criminal Policy in Iceland: Criminology on the Margins of Europe. Eur. J. Criminol. 2006, 3, 221-253. [CrossRef]

28. Dervishi, E.; Ibrahimi, S. Risk Factors Related to Juvenile Drug Use. OJPR 2018, 2, 53-60. [CrossRef]

29. McBride, A.A.; Joe, G.W.; Dwayne Simpson, D. Prediction of Long-Term Alcohol Use, Drug Use, and Criminality among Inhalant Users. Hisp. J. Behav. Sci. 1991, 13, 315-323. [CrossRef]

30. Wasserman, G.A.; Keenan, K.; Tremblay, R.E.; Coie, J.D.; Herrenkohl, T.I.; Loeber, R.; Petechuk, D. Risk and Protective Factors of Child Delinquency. 2003. Available online: https://www.ojp.gov/pdffiles1/ojjdp/193409.pdf (accessed on 15 April 2021).

31. United Nations Office on Drugs and Crime. Cocaine Trafficking in West Africa. The Threat to Stability and Development (with Special Reference to Guinea-Bissau); United Nations: New York, NY, USA, 2007. Available online: https://www.unodc.org/documents/ data-and-analysis/West\%20Africa\%20cocaine\%20report_10\%2012\%2007.pdf (accessed on 14 April 2021).

32. United Nations Development Programme. Human Development Report 2020. The Next Frontier Human Development and the Anthropocene; United Nations: New York, NY, USA, 2020. Available online: http://hdr.undp.org/sites/default/files/hdr2020.pdf (accessed on 15 April 2021).

33. Chabal, P.; Green, T. Guinea-Bissau. Micro-State to "Narco-State"; Hurst \& Company: London, UK, 2016.

34. Fragile States Index. Country Dashboard. 2021. Available online: https://fragilestatesindex.org/country-data/ (accessed on 15 February 2021).

35. Crundall, I.A. Student Perceptions of the Danger of Drug Use: A Factor Analysis. J. Drug Educ. 1992, 22, 147-153. [CrossRef] [PubMed] 
36. CIA. Guinea-Bissau-The World Factbook. 2021. Available online: https://www.cia.gov/the-world-factbook/countries/guineabissau/\#people-and-society (accessed on 15 February 2021).

37. United Nations Children's Fund. Education. 2021. Available online: https://www.unicef.org/guineabissau/education (accessed on 15 February 2021).

38. Kristjánsson, A.L.; Mann, M.J.; Sigfússon, J.; Thorisdóttir, I.E.; Allegrante, J.P.; Sigfúsdóttir, I.D. Implementing the Icelandic Model for Preventing Adolescent Substance Use. Health Promot. Pract. 2019, 1-10. [CrossRef]

39. Prichard, J.; Payne, J. Alcohol, Drugs and Crime: A Study of Juveniles in Detention; Research and Public Policy Series: No. 67; Australian Institute of Criminology: Canberra, Australia, 2005. Available online: https://www.aic.gov.au/sites/default/files/20 20-05/rpp067.pdf (accessed on 15 April 2021).

40. Webster, C. Predicting Criminality? Risk Factors, Neighbourhood Influence and Desistance. Youth Justice 2006, 6, 7-22. [CrossRef]

41. IBM. Pooled Results Not Produced for R-Square and SEE Values with Multiple Imputation. 2021. Available online: https: //www.ibm.com/support/pages/pooled-results-not-produced-r-square-and-see-values-multiple-imputation (accessed on 24 March 2021).

42. United Nations Children's Fund. Convention on the Rights of the Child Text. 2021. Available online: https://www.unicef.org/ child-rights-convention/convention-text (accessed on 15 June 2021).

43. Einarsdóttir, J. Tired of Weeping: Mother Love, Child Death, and Poverty in Guinea-Bissau, 2nd ed.; University of Wisconsin Press: Madison, WI, USA, 2004; ISBN 978-0-299-20134-0.

44. Gunnlaugsson, G.; Whitehead, T.A.; Baboudóttir, F.N.; Baldé, A.; Jandi, Z.; Boiro, H.; Einarsdóttir, J. Use of Digital Technology among Adolescents Attending Schools in Bissau, Guinea-Bissau. Int. J. Environ. Res. Public Health 2020, 17, 8937. [CrossRef]

45. Galea, S.; Vlahov, D. Social Determinants and the Health of Drug Users: Socioeconomic Status, Homelessness, and Incarceration. Public Health Rep. 2002, 117, 135-145. Available online: https://www.ncbi.nlm.nih.gov/pmc/articles/PMC1913691/ (accessed on 14 April 2021).

46. United Nations Educational, Scientific and Cultural Organisation. Guinea-Bissau: Education and Literacy. 2021. Available online: http:/ / uis.unesco.org/en/country/gw (accessed on 15 February 2021).

47. Sachsida, A.; de Mendonça, M.J.C.; Loureiro, P.R.A.; Gutierrez, M.B.S. Inequality and Criminality Revisited: Further Evidence from Brazil. Empir. Econ. 2010, 39, 93-109. [CrossRef]

48. United States Department of State. Guinea-Bissau 2018 Human Rights Report Country Reports on Human Rights Practices for 2018. Available online: https:/ /www.state.gov/wp-content/uploads/2019/03/Guinea-Bissau-2018.pdf (accessed on 14 April 2021).

49. United Nations Children's Fund. Republic of Guinea Bissau Executive Summary. 2017. Available online: https:/ /www.unicef. org/about/annualreport/files/Guinea_Bissau_2017_COAR.PDF (accessed on 14 April 2021).

50. Aguirre-Molina, M.; Gorman, D.M. Community-Based Approaches for the Prevention of Alcohol, Tobacco, and Other Drug Use. Annu. Rev. Public Health 1996, 17, 337-358. [CrossRef]

51. Strang, J.; Babor, T.; Caulkins, J.; Fischer, B.; Foxcroft, D.; Humphreys, K. Drug Policy and the Public Good: Evidence for Effective Interventions. Lancet 2012, 379, 71-83. [CrossRef]

52. Fleming, C.B.; White, H.R.; Catalano, R.F. Romantic Relationships and Substance Use in Early Adulthood: An Examination of the Influences of Relationship Type, Partner Substance Use, and Relationship Quality. J. Health Soc. Behav. 2010, 51, 153-167. [CrossRef] [PubMed]

53. Bodin, M.C.; Strandberg, A.K. The Örebro Prevention Programme Revisited: A Cluster-Randomized Effectiveness Trial of Programme Effects on Youth Drinking. Addiction 2011, 106, 2134-2143. [CrossRef]

54. Koning, I.M.; van den Eijnden, R.J.; Verdurmen, J.E.; Engels, R.C.; Vollebergh, W.A. Long-Term Effects of a Parent and Student Intervention on Alcohol Use in Adolescents: A Cluster Randomized Controlled Trial. Am. J. Prev. Med. 2011, 40, 541-547. [CrossRef]

55. Armiya'u, A.Y. Topic: Drug Abuse and Crime in West Africa. What Prospects? Drugs West Afr. Insight 2015, 4, 3-10. Available online: https:/ / cddelibrary.org/wp-content/uploads/2018/West\%20Africa\%20Insight\%20edition\%20on\%20Drugs\%202015.pdf (accessed on 15 April 2021).

56. International Centre for the Prevention of Crime. Prevention of Drug-Related Crime Report. 2015. Available online: https://www. unodc.org/documents/ungass2016/Contributions/Civil/ICPC/Rapport_FINAL_ENG_2015.pdf (accessed on 15 April 2021).

57. Slutkin, G.; Ransford, C.; Decker, R.B. Cure violence: Treating violence as a contagious disease. In Envisioning Criminology: Researchers on Research as a Process of Discovery; Maltz, M.D., Rice, S.K., Eds.; Springer International Publishing: Cham, Switzerland, 2015; pp. 43-56. [CrossRef] 